DOI: https//doi.org/10.13037/ci.vol22n50.7371

\title{
Jornalismo na perspectiva de gênero: ollhares sobre a editoria In Her Words do jornal The New York Times
}

\author{
Journalism from a gender perspective: looks at the In Her Words section of The New
} York Times

\author{
Albertina Vieira de Melo Gomes Oliveira ${ }^{\text {ai }}$ \\ ORCID: https://orcid.org/0000-0002-2725-4719 \\ Cynthia Mara Miranda ${ }^{\text {bii }}$ \\ ORCID: https://orcid.org/0000-0002-9399-7975
}

Recebido em 20/02/2021. Aprovado em 29/06/2021.

\begin{abstract}
Resumo
$\mathrm{O}$ artigo analisa as temáticas e a linguagem trabalhadas no editorial de gênero In Her Words, do Jornal The New York Times, para compreender se há construção de textos jornalísticos com perspectiva de gênero. O método de análise de conteúdo permitiu que fosse analisado no veículo de comunicação, a produção de jornalismo na perspectiva de gênero no editorial de gênero In Her Words. Os resultados apontam a produção de um conteúdo com perspectiva de gênero, tanto na linguagem utilizada como na escolha das fontes e temas abordados na construção dos textos jornalísticos.
\end{abstract}

Palavras-chave: Jornalismo na perspectiva de gênero. Direitos das mulheres. The New York Times.

\section{Introdução}

O direito à comunicação preza que cada cidadã e cidadão possa ter voz ativa, opinião respeitada e representatividade. Os meios de comunicação de massa, nessa direção, deveriam garantir a representatividade de todas as camadas da população evitando invisibilidades e silenciamentos de grupos marginalizados para efetivar o direito à comunicação para todas $\mathrm{e}$ todos.

\footnotetext{
${ }^{\mathrm{a}}$ Universidade Federal do Tocantins. Tocantins/Brasil. E-mail: albertina.oliveira@uft.edu.br

${ }^{\mathrm{b}}$ Universidade Federal do Tocantins. Tocantins/Brasil. E-mail: cynthiamara@uft.edu.br
}

Keywords: Journalism from a gender perspective. Women's rights. The New York Times. 
Nesse sentido, o presente artigo se propõe a analisar a representação da mulher nos meios de comunicação, com foco no jornalismo na perspectiva de gênero. A democratização da comunicação é o caminho para ampliar a perspectiva de gênero nos meios de comunicação e os seus obstáculos vem sendo estudados há décadas. Desde 1995, o projeto de pesquisa Global Media Monitoring Project (GMMP) ${ }^{1}$ que realiza monitoramento das notícias no mundo, com enfoque nas mulheres nas notícias, tem se debruçado a cada cinco anos sobre os problemas que a falta da perspectiva de gênero impacta na produção das notícias no mundo. Em 2020, pela primeira vez, o Brasil foi incorporado ao GMMP, 12 equipes regionais de voluntárias trabalharam para selecionar, analisar e enviar os dados das notícias dos principais veículos de comunicação brasileiros que foram coletadas em jornal impresso, rádio, TV e internet. Desde que o projeto GMMP iniciou o monitoramento das notícias em 1995, observa-se que os obstáculos para uma representação justa e plural das mulheres estão muito longe de serem rompidos, o que torna o jornalismo, na perspectiva de gênero, uma estratégia importante para romper tais obstáculos.

A linguagem, como instrumento que pode atuar na perpetuação da desigualdade entre os gêneros, provoca efeitos duradouros no imaginário social, sendo a principal ferramenta dos meios de comunicação de massa para levar informações até o público. Maffia (2007), ao refletir sobre o potencial dos discursos, apresenta um questionamento sobre a utilização de palavras ditas "masculinas" na delimitação de direitos para ambos os sexos. Ainda de acordo com a autora, o universo do discurso nem sempre é o mesmo universo da realidade. Nesse sentido, expressões como "todos os homens nascem livre e iguais" não podem dar conta da realidade vivida pelas mulheres que ainda estão em desvantagem em muitos domínios societários.

Para Meuli (2017) em uma sociedade como a atual, onde a lógica sexista é o pilar do sistema cultural e atua como força para a estruturação, manejo e organização de outros sistemas, é comum que os meios de comunicação de massa reproduzam o sexismo, imagens estereotipadas e preconceituosas das mulheres já que estão inseridos nesse sistema cultural onde a desigualdade entre os gêneros impera. Assim, problematizar sobre a representação da imagem das mulheres na mídia é um exercício necessário para impulsionar transformações

A adoção da comunicação inclusiva e não sexista tem avançado em vários países do mundo e aqui destacamos iniciativas no âmbito do jornalismo na América Latina e no mundo,

\footnotetext{
${ }^{1}$ O Global Media Monitoring Project (GMMP) é um projeto mundial de monitoramento, pesquisa e defesa da mídia de base. Foi inicialmente inspirado pela preocupação de mulheres ativistas em trazer a questão da responsabilidade da mídia para o primeiro plano do debate sobre as desigualdades de gênero. Disponível em: https://whomakesthenews.org/.
} 
como a criação de editorias de gênero em jornais de grande alcance como a editoria de gênero no jornal argentino Clarin ${ }^{1}$ e no jornal peruano La Repubblica ${ }^{2}$. Nos Estados Unidos destacase a iniciativa do jornal Financial Times ${ }^{3}$, que informa aos/as seus/as jornalistas quando o texto tem mais fontes masculinas do que femininas, já o jornal americano USNews ${ }^{4}$ tem espaço que publica semanalmente texto abordando a perspectiva de gênero sobre diversos aspectos.

No Canadá, a organização não governamental Informed Opinions, publica periodicamente um relatório intitulado Gender Gap Tracker ${ }^{5}$ no qual disponibiliza a quantidade de fontes masculinas e femininas que os veículos de comunicação utilizam ao produzir seus textos. O portal mexicano Malvestidas ${ }^{6}$ oferece textos relevantes sobre questões femininas que ainda são tabus na sociedade para problematizar sobre a necessidade de avançar na igualdade entre os gêneros. No Brasil, podemos destacar o Portal Catarinas ${ }^{7}$, especializado em jornalismo na perspectiva de gênero e a iniciativa $\mathrm{Az} \mathrm{Mina}^{8}$ que oferece jornalismo inclusivo e com perspectiva de gênero.

A adoção de políticas públicas, nessa direção, seria uma forma de reconhecimento que o universo do discurso não é o mesmo universo da realidade e, portanto, precisa incorporar especificidades foram negadas durante séculos para as mulheres.

Trata-se, portanto, de uma questão política e de incorporação de mais da metade da população mundial, ou seja, não pode ser vista apenas como uma questão gramatical e os meios de comunicação estão totalmente inseridos nesse contexto, já que por meio da linguagem podem reforçar e propagar desigualdades.

Por conseguinte, é objetivo deste estudo analisar as temáticas e a linguagem trabalhadas dentro do editorial de gênero (In Her Words) do jornal americano The New York Times para compreender o processo de construção do jornalismo na perspectiva de gênero na prática jornalística. A escolha de ter a In Her Words como ponto de partida para compreender as bases do jornalismo na perspectiva de gênero fundamenta-se no seu protagonismo na difusão das referidas temáticas e no seu alcance mundial.

\footnotetext{
${ }^{1}$ Disponível em: https://www.clarin.com/sociedad/editora-genero-desigualdadesestereotipos_0_xJz6APt7R.html. Acesso em: 7 mai de 2021.

${ }^{2}$ Disponível em: https://larepublica.pe/opinion/2020/09/18/red-feminista-contra-la-violencia-por-lucia-solisreymer-la-republica/. Acesso em: 7 mai de 2021.

${ }^{3}$ Disponível em: https://www.theguardian.com/media/2018/nov/14/financial-times-tool-warns-if-articles-quotetoo-many-men. Acesso em: 7 mai de 2021

${ }^{4}$ Disponível em: https://www.usnews.com/topics/subjects/gender. Acesso em: 7 mai de 2021

${ }^{5}$ Disponível em: https://gendergaptracker.informedopinions.org/. Acesso em: 7 mai de 2021.

${ }^{6}$ Disponível em: https://malvestida.com/. Acesso em: 7 mai de 2021.

${ }^{7}$ Disponível em: https://catarinas.info/. Acesso em: 7 mai de 2021.

${ }^{8}$ Disponível em: https://azmina.com.br/. Acesso em: 7 mai de 2021.
} 


\section{Albertina Vieira de Melo Gomes Oliveira}

A proposta metodológica de Bardin (2011), a análise de conteúdo, fundamentou o estudo a partir da análise de um corpus composto por 68 textos jornalísticos coletados no período de 28 de abril de 2018 a 28 de abril de 2019. O recorte temporal contemplou a data de lançamento do editorial e o seu primeiro ano. Os textos foram selecionados sem a utilização de descritores e cada um deles foi analisado integralmente.

A discussão aqui proposta, nessa direção, busca refletir sobre o jornalismo na perspectiva de gênero a partir das temáticas e da linguagem utilizadas na editoria In Her Words. Diante disso, o primeiro tópico contextualiza o jornalismo na perspectiva de gênero, na sequência serão apresentados os resultados da análise das notícias e nas considerações finais apresentamos alguns apontamentos sobre o jornalismo na perspectiva de gênero como ferramenta de inclusão.

\section{Jornalismo na perspectiva de gênero}

O jornalismo em pleno século XXI ainda apresenta uma cultura profissional majoritariamente formada e conduzida por homens em muitos países do mundo, especialmente nos cargos gerenciais e no topo da carreira em posições mais remuneradas e valorizadas, mesmo que as mulheres sejam a maioria nos cursos de jornalismo e nas redações (WOITOWICZ; ROCHA, 2018).

Pensar um jornalismo na perspectiva de gênero implica reconhecer a necessidade da incorporação de uma linguagem inclusiva e não sexista, aumentar o número de fontes femininas ouvidas nas notícias, observar as pessoas das notícias e entender se há equidade em relação à representatividade e representação, adotar flexão de gênero na linguagem, desenvolver uma linguagem não sexista, entre outras estratégias.

Em outra direção, mesmo reconhecendo a importância do jornalismo na perspectiva de gênero, para romper com obstáculo da falta de representatividade das mulheres nos meios de comunicação observa-se que as grandes empresas jornalísticas estão alicerçadas dentro da lógica do capital, são movidas pelo lucro e, portanto, mudanças que não geram lucros imediatos costumam ser preteridas.

A adoção de uma perspectiva de gênero nas narrativas jornalistas, nesse sentido, implica investimento e não é uma pauta que vai render lucro se levar em consideração a hierarquia dos valores notícias. Traquina (2005) considera que o conjunto de valores notícia determina os critérios de noticiabilidade. Ainda, segundo o autor, os valores notícia são um aspecto 
fundamental da cultura profissional jornalística, que constituem referências claras e disponíveis a conhecimentos práticos sobre a natureza e os objetos das notícias.

As empresas jornalísticas não estão dispostas a repensar suas práticas jornalísticas sem um lucro garantido. As poucas transformações que ocorrem no sentido de uma maior abertura para as questões de gênero surgem a partir de cobrança social e os movimentos feministas são fundamentais nessa direção. A editoria In Her Words, por exemplo, foi impulsionada pelas pautas feministas após escândalos sexuais que foram reverberados mundialmente, nos quais várias atrizes de Hollywood acusavam o então produtor Harvey Westein, de ataques sexuais. O movimento \#metoo foi o catalizador e fomentador que ofereceu esteio para as mulheres que se sentiam acuadas a fazer denúncia contra seus abusadores.

De acordo com a Women's Media Center -WMC, o panorama da mídia americana apresenta discrepâncias no sentido da equidade de gênero, $63 \%$ dos profissionais que assinam textos jornalísticos e recebem créditos por suas matérias veiculadas em veículos impressos, rádio internet e TV são homens, as mulheres configuram $37 \%$ do percentual total de profissionais no mercado. Em noticiários noturnos, as mulheres ocupam também apenas 37\% das posições. Na mídia impressa, as mulheres são $41 \%$, na internet $40 \%$ é composto por jornalistas mulheres.

Ruoho e Torkkola (2018), ressaltam a importância de analisar o papel sócio-histórico do jornalismo como uma instituição de gênero, que no geral, segundo as autoras, se apoia no sistema binário de gêneros, sistema esse que foi instituído na maioria das sociedades modernas. Tal análise, apresenta uma reflexão de que o jornalismo não seja então uma instituição neutra, e que pelo contrário, reforça a história do jornalismo como indutor da formação de cidadania e gênero.

A construção de um jornalismo na perspectiva de gênero, contudo, ultrapassa o campo da produção da escrita e deve atuar no contexto produtivo em que as notícias são produzidas; isso significa dizer que é preciso combater o assédio moral e sexual que as jornalísticas enfrentam no exercício profissional, ampliar o número de mulheres nos cargos de decisão e na cobertura de editorias que são mais reconhecidas e remuneradas como é o caso da política e da economia e ampliar a cobertura de assuntos que apresentam impacto na vida das mulheres.

\section{Análise da temática como ferramenta de perspectiva de gênero no jornalismo}

O recorte temporal de um ano escolhido para a pesquisa, possibilitou tecer reflexões sobre a construção do jornalismo na perspectiva de gênero a partir da linguagem e das temáticas 
pautadas pela editoria. No período da coleta dos dados a editoria publicava textos semanais (esporadicamente mais de um por semana) e no período de um ano foram selecionados 68 textos jornalísticos para compor o corpus deste estudo.

Concernente à linguagem, essa foi analisada a partir da perspectiva de características hegemônicas (características de linguagem do jornalismo tradicional) e não hegemônicas (características do jornalismo na perspectiva de gênero). Dessa forma, a linguagem hegemônica tem características relacionadas à violência de gênero, utilização de mais fontes masculinas para a construção da informação e utilização e reforço de estereótipos de gênero. Em contraponto, a linguagem não hegemônica preocupa-se em não criar ou reforçar estereótipos de gênero, utiliza na mesma proporção mulheres e homens como fontes das notícias e não promove a violência de gênero nos textos.

A coleta dos dados foi feita de forma manual na versão on-line do jornal The New York Times. Não foram usados descritores para a seleção, o critério utilizado para a seleção dos textos foi a publicação dele na editoria In Her Words dentro do recorte temporal determinado.

Após a coleta dos 68 textos, o material foi descarregado no programa MaxQda (software para análises qualitativas e quantitativas), a partir daí foi feita a leitura flutuante e a delimitação das categorias temáticas. O software permitiu que em todos os textos fossem feitas codificações e marcações que alimentaram as categorias.

Acerca da análise temática, é válido dizer que a categorização utilizada nesta pesquisa foi criada com base no referencial teórico dos estudos da comunicação e gênero (WALSH,2001; RODAL,2015; BOURDIEU,1992; BIROLI, 2018). Isso posto, serão descritas abaixo as categorias que serviram de direção para que fossem feitas as análises.

\begin{tabular}{|l|l|}
\hline \multicolumn{1}{|c|}{ Categoria } & \multicolumn{1}{c|}{ Descrição } \\
\hline Direito das mulheres & $\begin{array}{l}\text { Temas que abordassem os direitos das mulheres, aborto, ativismo feminino e todos } \\
\text { os temas relacionados ao movimento, liberdade de escolha e protagonismo } \\
\text { feminino. }\end{array}$ \\
\hline Política & $\begin{array}{l}\text { Temas que abordassem política, legislação, projetos de lei, decisões políticas sobre } \\
\text { diversos assuntos e decisões legais sobre diversos assuntos. }\end{array}$ \\
\hline Discriminação & $\begin{array}{l}\text { Temas que abordassem racismo, gordofobia, misoginia, religião e declarações } \\
\text { pejorativas e preconceituosas. }\end{array}$ \\
\hline Autoestima & $\begin{array}{l}\text { Temas ligados ao reconhecimento do poder e das possibilidades da mulher, beleza, } \\
\text { padrões, sororidade, orgulho LGBTQ, bodypositive, amor e mulheres inspiradoras. }\end{array}$ \\
\hline Violências & $\begin{array}{l}\text { Temas que abordassem as violências de diversas formas: assédio, estupro, e } \\
\text { exploração sexual. }\end{array}$ \\
\hline Dicotomia & $\begin{array}{l}\text { Temas que abordassem as diferenças salariais, patriarcado, preconceito contra as } \\
\text { mulheres, padrões culturais limitantes, carreira, filhos, casamento, jornadas } \\
\text { múltiplas, tarefas e direitos com base no gênero. }\end{array}$ \\
\hline
\end{tabular}

Quadro 1 - Categorias temáticas

Fonte: categorias elaboradas pelas autoras 
Após a delimitação das categorias e a alocação dos textos codificados em cada uma delas, o software, com base nas codificações feitas pelas pesquisadoras, ofereceu um panorama acerca dos percentuais referentes às codificações.

Dito isso, abaixo será explorada a análise temática feita pelas autoras, bem como no gráfico 1 serão apresentados os percentuais de acordo com a ocorrência deles na In Her Words.

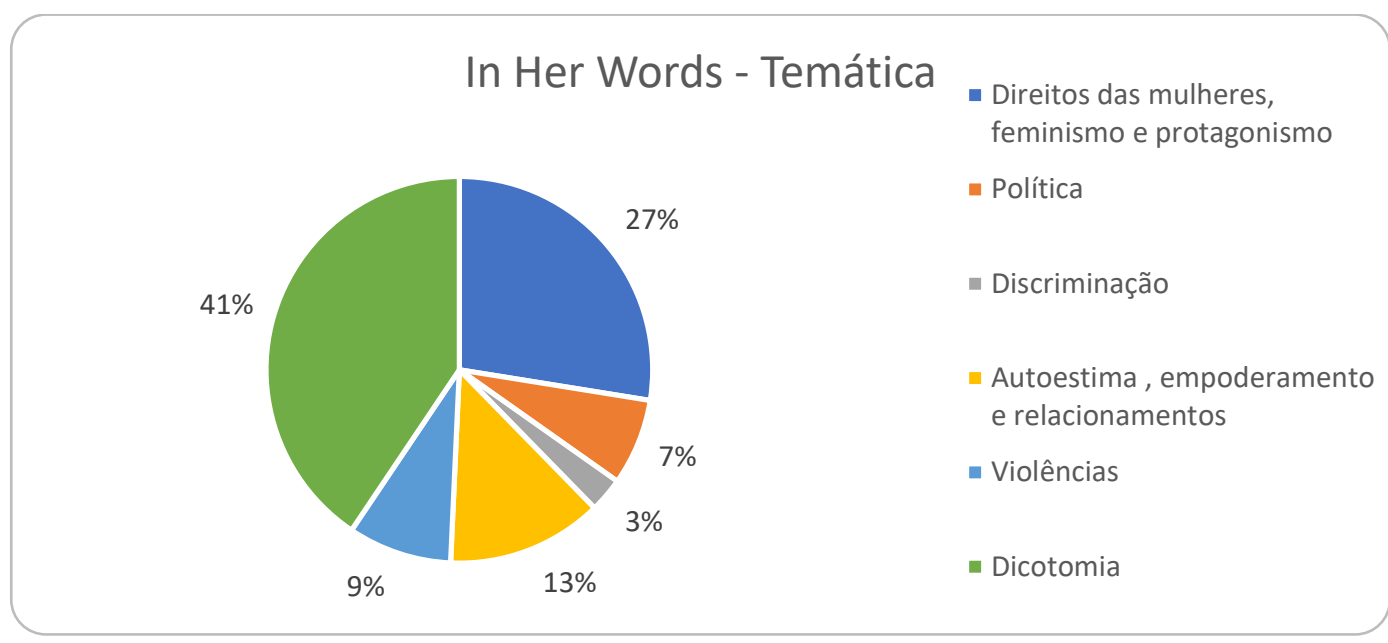

Gráfico 1 Análise das temáticas da In Her Words

Fonte: Gráfico elaborado pelas autoras.

As temáticas trabalhadas pela In Her Words oferecem uma percepção sobre quais assuntos são pertinentes naquele espaço. Com $41 \%$ de ocorrência, a categoria Dicotomia prevê os temas que tencionam as relações de gênero dentro dos espaços públicos e privados, dessa forma, a discussão de tais temas se propõe a ser um agente provocador de reflexões a respeito dessa dicotomia. Sendo assim, pode-se dizer que as temáticas também podem ocorrer de forma a direcionar o jornalismo para um local de combate, de projeção das diferenças propostas pelo patriarcado, questionando de forma preponderante a hegemonia vivenciada hodiernamente.

As demais categorias abordam, de forma menos prevalente, questões referentes às relações de gênero, mas não menos importantes por estarem em menor proporção, quanto à forma de distribuição nas publicações. A categoria direito das mulheres apareceu com o percentual de $27 \%$, a categoria autoestima com $13 \%$, a categoria violências aparece com $9 \%$, a categoria política aparece com $7 \%$ e com $3 \%$ aparece a categoria discriminação.

De acordo com as temáticas expostas acima, percebe-se que a editoria busca oferecer um equilíbrio entre os temas relacionados às questões inseridas dentro da dicotomia públicoprivada e os direitos das mulheres. Não obstante, as demais categorias complementam e agem como agentes de tensão e questionamento contínuos, sobre como e quais são as formas de representar a mulher na mídia. 


\section{Albertina Vieira de Melo Gomes Oliveira}

Cabe ressaltar que, apesar de a categoria violências reunir temas relacionados às diversas formas pelas quais as mulheres podem sofrer violência, algumas violências sofridas pelas mulheres são subjetivas e por isso, muitas vezes não são "corporificadas" por falta de supostas evidências e pela facilitação do sistema patriarcal e hegemônico em descredibilizar as falas femininas.

Adiante, será apresentada a análise da linguagem desenvolvida nos textos publicados no editorial de gênero In Her Words.

\section{Análise da linguagem como ferramenta de perspectiva de gênero no jornalismo}

De acordo com Gramsci (2000), os veículos de comunicação são considerados aparelhos privados de hegemonia, dito isso, percebe-se a relevância sobre o que é noticiado e como é noticiado, posto que, ainda de acordo com o autor, o bloco hegemônico concatena e inculca em outros grupos sociais um ideal universalizado acerca das consciências ética e política.

Para De Moraes (2010) a construção da hegemonia na contemporaneidade é baseada cada vez mais em disputas ideológicas e culturais, responsáveis por influenciar e condicionar o imaginário social, assim como influenciar os sentidos de compreensão pela sociedade. É relevante destacar aqui, o papel dos media como difusores de pensamentos e ideais.

Rodal (2015), complementa que a hegemonia se constitui por meio de vários mecanismos, e que eles têm relação direta com a influência dos meios de comunicação, sendo que os media são capazes de criar temáticas de preocupação coletiva, direcionando os temas sobre os quais devemos pensar e quais devem ser as nossas preocupações. Ainda, de acordo com a autora, a hegemonia desenvolve símbolos reconhecíveis e metáforas que sublimam certos comportamentos ou atos rituais, e dessa forma delineiam os lugares que cada grupo ou classe pode ocupar na sociedade.

Diante dos pontos explorados acima entende-se a relevância da linguagem, no que tange às relações de gênero, e o papel preponderante dos media em posições contra-hegemônicas, especialmente quando se trata da reprodução e representação das mulheres em grandes veículos de comunicação, meios em que tradicionalmente predomina a linguagem masculinista, considerada hegemônica.

Para a análise da linguagem foram observadas a forma como as vítimas de violência são expostas no texto, no sentido de não corroborar com a exposição da vítima, de não criar estigmas e ou estereótipos femininos limitantes, de não desacreditar o discurso feminino, de dar voz às mulheres e da utilização de fontes femininas para a produção dos textos, permitindo 
assim representação e representatividade da mulher na mídia.

Ainda em relação à análise da linguagem (entendemos que romper com os padrões hegemônicos de reprodução das notícias também é utilizar a linguagem como forma de resistência) e por isso analisamos também o tipo das fontes utilizadas no editorial In Her Words.

O gráfico abaixo demonstra de que forma foram utilizadas as fontes nos textos jornalísticos.

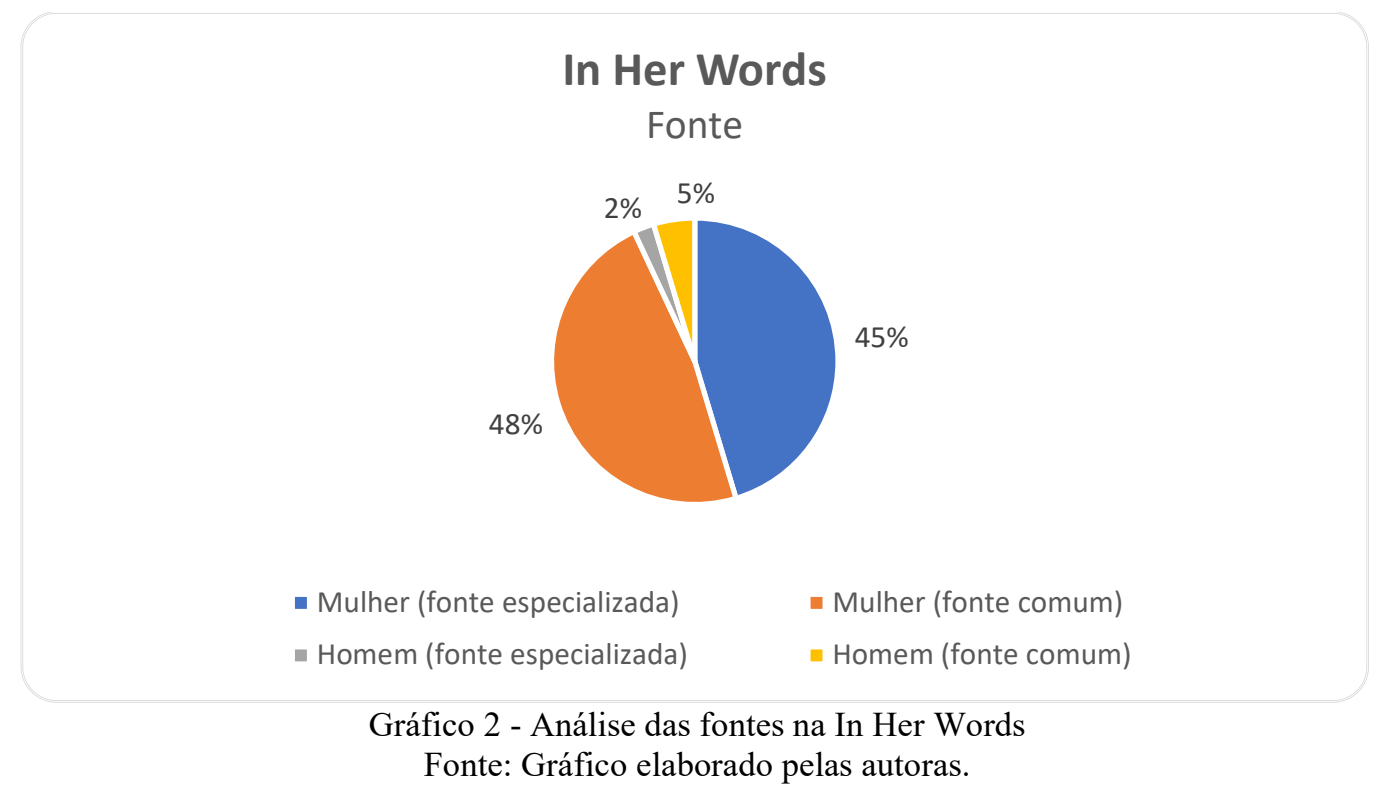

No gráfico acima, é notória a presença feminina como fonte dos textos publicados pela editoria. Decerto, deve-se levar em consideração o conteúdo ser direcionado ao público feminino, no entanto, não deixa de ser um ato de contra-hegemonia e de resistência trazer em sua grande maioria mulheres como fontes especializadas e mulheres como fontes comuns de notícias em um veículo de comunicação de grande relevância mundial como o The New York Times.

Nos trechos selecionados abaixo, entende-se que a história sobre e para as mulheres são contadas por elas mesmas, em suas próprias perspectivas e utilizando a linguagem como forma de normalização da presença feminina em ambientes considerados masculinistas.

Na categoria Dicotomia, no texto publicado no dia 9 de agosto de 2018, sob o título Rebel Women Are Coming to a Public Monument Near You, a jornalista Maya Salam questiona a respeito da falta de representatividade das mulheres na história. A autora alega que existem 5.200 estátuas públicas representando figuras históricas e menos de 400 dessas estátuas são mulheres. Cita ainda, que durante uma exposição no Museu da Cidade de Nova York, chamada Mulheres Rebeldes, pouco sabia sobre algumas das mulheres que lá estavam representadas. A 
seguir, apresentamos trecho selecionado do texto enquadrado na categoria dicotomia que destaca as várias vertentes da desigualdade entre os gêneros.

\begin{abstract}
Essas mulheres buscaram o que muitas mulheres procuram hoje: status profissional, igualdade racial e social e liberdade sexual. Elas eram o meu tipo de pessoa! Então, como foi possível que eu não tivesse ouvido falar de pelo menos metade delas."Você não está sozinha", disse Alicia Glen, a vice-prefeita de Nova York, enquanto caminhávamos pela exposição. "Temos que ter representação física", explicou ela, para ajudar a preencher a lacuna em nossa memória coletiva ${ }^{9}$ (Tradução das autoras) (SALAM, 2018a, on-line s/p).
\end{abstract}

O texto oferece ao público leitor a possibilidade de conhecer um pouco a respeito das mulheres que estavam na exposição citada pela autora, e abre reflexões sobre o motivo pelo qual muitas mulheres ainda não estão sendo representadas como figuras históricas. $\mathrm{O}$ apagamento das mulheres, seja ele da história ou das notícias, é algo que se propagado, normaliza-se. Dito isso, cabe ressaltar a importância de falar a respeito das diferenças e romper as crenças limitantes que distanciam as mulheres de ocuparem os seus lugares na história e na sociedade.

O trecho acima demonstra a preocupação sociopolítica da editoria, empenhada em oferecer textos de conteúdo questionador no que se refere às divisões construídas socialmente e culturalmente pelo patriarcalismo. Fazer jornalismo na perspectiva de gênero pode ser considerada uma forma potente de questionamento de padrões limitantes.

Um ponto a ser destacado, por exemplo, é que a editoria americana trazia em grande parte dos textos uma referência a como o jornal NYT tratava determinado assunto em edições dos anos 50, 60, 70 e etc. Foi auspicioso colocar ali naquele espaço, a reflexão crítica ou não, acerca do que foi e como foi notícia no jornal em décadas anteriores. Dessa forma, a editoria parece promover um espaço de tensão dentro do veículo, como se estivesse continuamente provocando reflexões acerca das questões de gênero e sobre a necessidade de naturalização de tais questões.

No que diz respeito à história do jornal e a representação do feminino dentro do veículo, há um passado que não condiz com o que o The New York Times propõe a fazer atualmente. Em meados de 1955, as chamadas Women's Pages (Páginas Femininas - tradução das autoras) ou também, como ficaram conhecidas: 4F's Food, Fashions, Family, Furnishings (Comida, Moda, Família, móveis - tradução das autoras) eram escritas por mulheres e para mulheres. No

\footnotetext{
${ }^{9}$ These women sought what many women today seek: professional status, racial and social equality, and sexual freedom. They were my kind of people! So how was it possible that I hadn't heard of at least half of them? "You're not alone," Alicia Glen, the deputy mayor of New York, said to me as we walked through the exhibit. "We have to have physical representation," she explained, to help fill the gap in our collective memory.
} 
entanto, as jornalistas eram mantidas no nono andar do edifício do jornal, separadas do restante dos profissionais homens que trabalhavam nas demais seções.

Mesmo com a presença de um editorial que tem suas bases no jornalismo na perspectiva de gênero, não há paridade na empresa The New York Times, quando se fala em mulheres nas posições de liderança dentro da organização. O veículo aponta, em seu Relatório anual de diversidade e inclusão ${ }^{10}$, realizado em 2019 , que apesar de haver $51 \%$ de mulheres no expediente do jornal, ainda há um hiato no que tange à representação feminina dos cargos de chefia, nos quais apenas $40 \%$ são mulheres.

Percebe-se, então, um movimento no jornal, a fim de buscar evocar um sentimento de promoção de equidade e um dever social de promover a naturalização da ocupação dos espaços pelas mulheres. No entanto, ainda há que se levar em consideração os apelos comerciais que tais iniciativas podem trazer consigo.

$\mathrm{Na}$ categoria Direitos das Mulheres, a editoria In Her Words buscou apresentar textos que trouxessem pertencimento para as (os) leitoras (es), partindo do pressuposto de que é sempre possível ter mais informação sobre os direitos das mulheres. No texto What Is the Equal Rights Amendment, and Why Are We Talking About it now?, a jornalista Maya Salam busca aproximação como público leitor ao dizer que sabe tudo sobre o tema e que sempre é tempo para as mulheres aprenderem sobre os seus direitos.

Você entende a Emenda de Direitos Iguais? Essa tem sido a minha pergunta preferida
para usar na festa ultimamente e, para minha surpresa, a maioria das pessoas não se
desculpa por não saber responder, quando perguntada. As respostas mais comuns que
ouvi, especialmente de mulheres da minha idade, foram: "Já não temos isso?" ou,
"Isso foi coisa dos anos 70 , certo?" Na verdade, não o tínhamos - e não era apenas
uma coisa dos anos 70 . E, no entanto, até recentemente, eu também não tinha ideia do
que era. (Sinto muito às minhas amigas feministas, jovens e velhas, que certamente
estão horrorizadas com essa lacuna no conhecimento. O capítulo estava ausente de
meus livros de história, sem surpresa.) Então, perguntei a dois lí́leres E.R.A.
advogados, Carol Jenkins e Carol Robles-Román, para explicar o que é a Emenda de
Direitos Iguais e por que estamos falando sobre ela ${ }^{11}$ (Tradução das autoras)
(SALAM, 2019a, on-line s/p). É relevante para a percepção da mulher e para a percepção social do que é a promoção

\footnotetext{
${ }^{10}$ Disponível em: https://www.nytco.com/company/diversity-and-inclusion/2019-diversity-and-inclusion-report/. Acesso em: $16 \mathrm{dez} 2021$.

11 Do you understand the Equal Rights Amendment? That's been my go-to party question lately, and to my surprise, most people don't politely excuse themselves for a refill when asked. The most common responses I've heard, especially from women my age, were to the effect of: "Don't we already have that?" or "That was a '70s thing, right?" In fact, we don't have it - and it wasn't just a '70s thing. And yet until recently, I too had little idea what it was. (Sorry to my feminist friends, young and old, who are surely horrified by this gap in knowledge. The chapter was unsurprisingly absent from my history books.) So, I asked two leading E.R.A. advocates, Carol Jenkins and Carol Robles-Román, to explain what the Equal Rights Amendment is and why we're talking about it.
} 
de espaços igualitários, que os espaços públicos sejam preenchidos também por figuras femininas que tiveram papéis importantes para a sociedade como um todo. As mulheres precisam conhecer a história de outra perspectiva, como sendo a própria mulher a escritora e narradora de seus fatos.

Direitos das mulheres, nesse sentido, implica no reconhecimento dos direitos conquistados pelas mulheres ao longo de décadas. Reivindicações das mulheres organizadas nos movimentos feministas em várias partes do mundo resultaram no questionamento da sua condição de vida em diversas direções como no direito de dispor do próprio corpo, a justiça, o poder, a participação. Tais questionamentos foram fundamentais para a construção de políticas públicas de igualdade como a licença maternidade, as creches públicas e as cotas para participação nos cargos eletivos, por exemplo.

Mais uma vez, é relevante a presença de mulheres como fontes de informações para a construção dos textos publicados no editorial essencialmente em se tratando do discurso acerca dos direitos conquistados ao longo de décadas.

Na categoria Autoestima, a In Her Words publicou no dia 11 de outubro de 2018 o texto What 18 Looks Like Around the World - Through Girls' Eyes, que promove um vislumbre acerca dos 18 anos de várias meninas ao redor do mundo, e como cada uma, a seu modo percebe a si e ao mundo. Exercitando o olhar e o empoderar-se.

\footnotetext{
Hoje lançamos “This Is 18”, um projeto para capturar como é a vida de meninas que completam 18 anos em 2018 em oceanos e culturas - no México e Mississippi, Ramallah e Rússia, Bangladesh e no Bronx. Como muitas de nós, as meninas apresentadas neste projeto - mulheres jovens - estão descobrindo quem são e quem querem $\operatorname{ser}^{12}$ (Tradução das autoras) (BENNETT,2018a, on-line s/p).
}

O desenvolver nas mulheres o hábito de se olharem e se perceberem enquanto indivíduos capazes e hábeis para adentrar os espaços, começa quando há o fortalecimento da imagem que essas mulheres têm de si mesmas. A força e a vontade de fazerem parte história que também é feita por elas. A beleza em si está também no empoderar-se.

Para Sardenberg (2015) o empoderamento das mulheres pode ser visto tanto como um processo pelo qual as mulheres conquistam autonomia, quanto como um instrumento para o desmonte das estruturas patriarcais. Nesse sentido, a autoestima das mulheres pode atuar como estratégia para a desconstrução das relações de poder desiguais entre os gêneros, a autoestima

\footnotetext{
12 Today we launched "This Is 18," a project to capture what life is like for girls turning 18 in 2018 across oceans and cultures - in Mexico and Mississippi, Ramallah and Russia, Bangladesh and the Bronx. Like many of us, the girls featured in this project - young women - are figuring out who they are, and who they want to be 128
} 
que emerge no plano pessoal pode alcançar o plano coletivo e transformar em uma ação política capaz de transformar os valores sociais.

Mais uma vez, a utilização da linguagem representa uma ferramenta para dar visibilidade às mulheres em diversas partes do mundo e de diferentes culturas, unindo-as por meio de um projeto que celebra a liberdade de escolha em ser livre para escolher qual caminho seguir, seja ele pessoal, profissional ou educacional.

Quando analisada a categoria Violências, foi percebido que muitos casos eram relacionados a assédios e que não houve fotos de vítimas e nem tampouco exposição da mulher em relatos feitos pelas jornalistas, o que demonstra o compromisso com o jornalismo na perspectiva de gênero. Não foi encontrado nos textos, casos de agressão e ou feminicídio. No dia 11 de maio de 2018 o texto 5 Stories of Sex and Consent on Campus, trazia uma série de relatos, como o que será disposto abaixo.

\footnotetext{
'Ele parecia não saber o que a palavra 'consentimento' significa”. Essa é uma das citações que me saltaram à atenção de um artigo condenatório publicado pela The New Yorker na segunda-feira. Quatro ex-namoradas do procurador-geral de Nova York, Eric Schneiderman, acusaram-no de abuso sexual, descrevendo em detalhes assustadores como Schneiderman as esbofeteou e as estrangulou, às vezes durante $o$ sexo, e abusou delas verbal e emocionalmente. Ele renunciou três horas após a publicação da história ${ }^{13}$ (Tradução das autoras) (BENNETT,2018, on-line s/p).
}

No trecho acima, percebe-se que a jornalista adota um tom mais crítico para abordar uma situação que foi exposta por outro veículo e propõe aos (às) leitores (as) uma reflexão sobre o termo consentimento, ao trazer parte do relato de uma das vítimas para o texto publicado na In Her Words. É relevante que a profissional que se proponha a fazer jornalismo na perspectiva de gênero, promova o estranhamento a situações como a descrita acima, questionando e fomentando o debate público sobre os limites legais e sobre os direitos das mulheres.

Ainda no trecho acima, é possível perceber a presença de linguagem hegemônica utilizada por outro veículo (citado por Bennett no trecho selecionado), quando as violências são detalhadas de formas desnecessárias, o que não agrega valor à notícia e apenas revitimiza a vítima.

A categoria Violências diz respeito ao problema mais amplo vivenciado pelas mulheres

\footnotetext{
13 "He seemed not to know what the word 'consent' means". That's one of the quotes that jumped out at me from a damning article published by The New Yorker on Monday. Four former girlfriends of New York Attorney General Eric Schneiderman accused him of sexual abuse, describing in chilling detail how Mr. Schneiderman slapped them and choked them, sometimes during sex, and verbally and emotionally abused them. He resigned three hours after the story was published
} 
no mundo. Desde o nascimento até a velhice, mulheres têm sido vítimas de distintas formas de violência sejam psicológica, física, patrimonial ou sexual. Conforme Saffioti (1976), a violência deve ser compreendida num contexto ampliado e se dá em espaços e situações variadas. Para Hirata e Laborie (2009, p. 173),

o patriarcado designa uma formação social em que os homens detêm o poder, ou ainda, mais simplesmente, o poder é dos homens. Ele é, assim, quase sinônimo de "dominação masculina" ou de opressão das mulheres. Essas expressões, contemporâneas dos anos 70, referem-se ao mesmo objeto, designado na época precedente pelas expressões "subordinação" ou "sujeição" das mulheres, ou ainda "condição feminina".

A raiz da violência de gênero é a desigualdade entre homens e mulheres, e se manifesta nas relações sociais e é constantemente reforçada nos meios de comunicação. A violência contra as mulheres tem suas bases no patriarcalismo que ao longo dos tempos garantiu poder aos homens e a sujeição das mulheres.

Na categoria Política, o texto A Record 117 Women Won Office, Reshaping America's Leadership, publicado em 7 de novembro de 2018 trata sobre o recorde de mulheres eleitas.

O recorde de 117 mulheres ganhou as eleições nos Estados Unidos na terça-feira, trocando cadeiras e assumindo nomes. Os eleitores, que votaram de forma importante, entregaram coletivamente o controle da Câmara dos Representantes aos democratas, e 17 das 27 cadeiras que conquistaram até agora serão ocupadas por mulheres. Os republicanos fortaleceram sua maioria no Senado, ganhando duas cadeiras, uma das quais foi para Marsha Blackburn, que será a primeira senadora do Tennessee ${ }^{14}$ (Tradução das autoras) (SALAM, 2018b, on-line s/p).

A relevância de temas e de jornalistas que tratem com perspectiva de gênero as ocasiões em que as mulheres adentrem aos espaços públicos, esteve sempre presente nos textos publicados pela In Her Words. Mais do que conseguir ocupar os espaços de poder, é necessário que se institucionalize e se normalize situações assim e que sempre sejam promovidos debates sobre a necessidade de cada vez mais mulheres fazerem parte dos espaços políticos. Da mesma forma, trazer essas mulheres como fontes das notícias, reforça a presença delas nos espaços políticos e reafirmam a presença e o trânsito das mulheres dentro dos espaços públicos e privados.

Miguel e Biroli (2015) afirmam que as lutas feministas sempre tiveram estreita relação com as conquistas das mulheres nas arenas sociais e políticas. No entanto, os autores citam que

14 Record 117 women won elections across the United States on Tuesday, flipping seats and taking names. Voters, who turned out in a major way, collectively gave control of the House of Representatives to Democrats, and 17 of the 27 seats they've gained so far will be filled by women. Republicans strengthened their majority in the Senate, gaining two seats, one of which went to Marsha Blackburn, who will be Tennessee's first female senator. 
ainda não há representatividade das mulheres em espaços de poder, mesmo após tantos direitos já conquistados pelas mulheres. Ainda, de acordo com Miguel e Biroli (2015), é necessário se despir dos estereótipos inculcados pelo patriarcado e entender que mulheres estão interessadas em política e que podem ser representadas como um grupo em todos os âmbitos da política.

Na categoria Discriminação, o texto Trolls Tried to Sink 'Captain Marvel.' She Triumphed, publicado no dia 15 de março de 2019 e no qual é possível perceber o preconceito, discriminação e misoginia promovido por um grupo de pessoas que buscou "derrubar" a classificação do filme da Marvel, no qual a heroína capitã Marvel é a protagonista.

\begin{abstract}
Os trolls tentaram derrubar o novo filme "Capitão Marvel" - mas no final, a shero Carol Danvers (que é o Capitão Marvel nos quadrinhos desde 2012) prevaleceu. O filme ultrapassou US \$500 milhões em vendas de ingressos na primeira semana. ICYMI: Poucas horas após o lançamento do filme em 8 de março (Dia Internacional da Mulher), no que parecia ser um esforço concentrado, cerca de 58.000 críticas online de "Capitão Marvel" baixaram sua classificação no Rotten Tomatoes - deixando o filme com uma pontuação péssima de cerca de 30 por cento. O Rotten Tomatoes resolveu o problema naquela tarde, removendo cerca de 50.000 das críticas, que o site disse terem sido escritas antes do filme ser lançado. Entre outras medidas, o site eliminou rapidamente as avaliações de público de pré-lançamento ${ }^{15}$ (Tradução das autoras) (SALAM, 2019b, on-line s/p).
\end{abstract}

Foi percebido no texto, a busca por questionar os padrões patriarcais, ao evidenciar por meio da publicação a tentativa frustrada de um grupo, em prejudicar a estreia de um filme de uma heroína. Cabe aqui ressaltar, que a jornalista Maya Salam ainda publicou a palavra “SHERO” para se referir à atriz que interpreta a heroína capitã Marvel nos cinemas desde o ano de 2012, em uma clara tentativa de reproduzir uma linguagem inclusiva.

O trecho acima pode ser entendido como uma forma de corroborar com o que apregoa a Convenção sobre a Eliminação de Todas as Formas de Discriminação contra a Mulher (1979) para a qual a discriminação contra a mulher é compreendida como:

[...] toda a distinção, exclusão ou restrição baseada no sexo e que tenha por objeto ou resultado prejudicar ou anular o reconhecimento, gozo ou exercício pela mulher, independentemente de seu estado civil, com base na igualdade do homem e da mulher, dos direitos humanos e liberdades fundamentais nos campos político, econômico, social, cultural e civil ou em qualquer outro campo (FEDERAL, 1979, p.20).

15 Trolls tried to torpedo the new "Captain Marvel" movie — but in the end, the shero Carol Danvers (who's been Captain Marvel in the comic books since 2012) prevailed. The film sailed past $\$ 500$ million in ticket sales in its first week. ICYMI: Within hours of the movie's release on March 8 (International Women's Day), in what appeared to be a concerted effort, some 58,000 online reviews of "Captain Marvel" had tanked its rating on Rotten Tomatoes - leaving the film with an abysmal score of around 30 percent. Rotten Tomatoes fixed the problem by that afternoon, removing about 50,000 of the reviews, which the site said had been written before the film was released. Among other measures, the site swiftly eliminated prerelease audience reviews altogether. 


\title{
Albertina Vieira de Melo Gomes Oliveira
}

Todas as formas de discriminação podem e devem ser combatidas, seja por meio da presença cada vez mais constante de mulheres nos media, seja pela utilização da linguagem como forma de combate aos preconceitos inerentes ao consensual hegemônico do patriarcado.

As pautas feministas estavam presentes na In Her Words, que após a análise, surge como um espaço pautado pelos movimentos feministas e buscando oferecer um jornalismo na perspectiva de gênero. Dessa forma, o caráter questionador dos movimentos feministas é o que realça a necessidade que essas mulheres têm de se colocarem como sujeitos da própria vida e da própria existência enquanto pessoas.

Destarte, um jornalismo que se proponha a ser pensado e realizado com uma perspectiva de gênero, deve ao menos manter a essência contestadora e buscar promover sempre a visibilidade das mulheres nos espaços públicos e reconhecer a importância das lutas feministas.

Ainda no tocante à linguagem, Cuba (2018) afirma que os movimentos feministas, em uma tomada de consciência, buscam maneiras de promover a linguagem como uma prática social, intrínseca a uma luta de poderes, esse movimento pode ser entendido como perspectiva e ou fenômeno glotopolítico.

Del Valle (2020) reforça a importância da linguagem como ferramenta de inclusão, e faz uso da perspectiva do glotopolítico para justificar a necessidade de uma mudança.

\begin{abstract}
Portanto, do ponto de vista glotopolítico, a quebra ou alteração da norma não se explica como ignorância gramatical, mas como visibilidade de uma posição social e como potencial construção e manifestação de sujeitos políticos. Esses momentos de transgressão linguística, em suma, são aqueles que desvelam a condição política socialmente situada e ligada a interesses específicos - da norma transgredida e desmascaram a ideologia política que, por trás do véu de naturalidade com que recobre a norma que guarda, ele se beneficia de sua reprodução acrítica ${ }^{16}$ (Tradução das autoras) (DEL VALLE, 2020, on-line s/p).
\end{abstract}

Apesar de não ter sido analisada a linguagem inclusiva nesta pesquisa, reforça-se a relevância da proposição dessa mudança capitaneada pelos movimentos feministas, do ponto de vista da inclusão e da representatividade das mulheres nos espaços sociais, políticos e bem como no que tange aos aspectos sociolinguísticos.

Cabe aqui ressaltar, que não foi encontrado na análise um texto com características de linguagem hegemônica publicado na In Her Words, o que pode de fato, revelar a preocupação

\footnotetext{
16 Por ello, desde una perspectiva glotopolítica, el incumplimiento o alteración de la norma no se explica como ignorancia gramatical sino como visibilización de una posición social y como potencial construcción y manifestación de sujetos políticos. Esos momentos de transgresión lingüística, en definitiva, son los que destapan la condición política - socialmente situada y ligada a intereses concretos - de la norma transgredida y desenmascaran a la ideología política que, tras el velo de naturalidad con que cubre la norma que custodia, se beneficia de su reproducción acrítica.
} 
e a observância da prática do jornalismo na perspectiva de gênero pelo corpo do editorial.

Diante dos fatos analisados, pode-se dizer que a editoria de gênero do jornal The New York Times busca trabalhar o jornalismo na perspectiva de gênero, muito embora esse novo modelo de jornalismo possa estar relacionado também a uma resposta comercial a um nicho de mercado cada vez mais crescente. Dessa forma, convém considerar que as temáticas e a linguagem trabalhadas neste espaço sugerem uma efetiva proposição de tensão em relação às questões de gênero dentro do jornalismo, bem como, uma ação positiva para transpor o jornalismo hegemônico e promover um pensamento mais crítico e inclusivo às questões de gênero.

As temáticas tiveram correspondência com as principais pautas dos movimentos feministas, no sentido de promoverem debate e reflexão sobre o papel da mulher como sujeito ativo dentro da dicotomia público-privada, dos direitos das mulheres e da importância de as mulheres entenderem e denunciarem abusos que estão ancorados no sistema patriarcal que rege a sociedade.

A título de informação, já que não constituiu o foco do estudo, dentro da análise realizada nos 68 textos do editorial, apenas 14 textos discutiam questões ligadas às mulheres negras. Como não houve uma abordagem mais incisiva nesse quesito, entende-se que a interseccionalidade poderia ter sido mais bem trabalhada no editorial, especialmente em se tratando de um meio que busca romper com os padrões hegemônicos vigentes nos media.

\section{Considerações Finais}

A editoria de gênero aqui analisada reivindica um modelo de jornalismo na perspectiva de gênero por meio da produção jornalísticas que versa sobre temáticas diversas, observando os temas ligados à pauta dos movimentos feministas e preconizando a utilização equilibrada de fontes nas notícias, bem como utilizando linguagem com características não hegemônicas.

Diante disso, pode-se afirmar que o veículo trabalha o jornalismo na perspectiva de gênero dentro da In Her Words, as temáticas e a linguagem utilizadas nas notícias analisadas apontaram que o jornal adotou estratégias para incorporar a perspectiva de gênero na produção jornalística.

O jornalismo tradicional tende a propagar a linguagem hegemônica, na qual as mulheres são invisibilizadas. A editoria, se pensada como um recorte e ou uma representação recortada da realidade, pode ser considerada uma das muitas formas de ver o mundo, partindo da ideia de que o mundo tem fenômenos políticos, econômicos e esportivos que precisam ser vistos a partir 


\section{Albertina Vieira de Melo Gomes Oliveira}

de uma perspectiva de gênero tendo em vista que as mulheres são mais da metade da população mundial.

A editoria de gênero do jornal The New York Times, nessa direção, reivindica e propõe um novo modelo de jornalismo, incluindo os temas de interesse de um pouco mais da metade da população mundial que dialoga diretamente com as pautas dos movimentos feministas.

Destarte, cabe ressaltar aqui que enquanto pesquisadoras, esta pesquisa nos ofereceu e possibilitou adentrar e observar uma nova possibilidade do fazer jornalístico. Perceber em um dos maiores jornais, em nível mundial, que há espaço para novas proposições e abertura para possibilidades reais, é uma grande satisfação, como mulher e como pesquisadora.

Dito isso, também é relevante pensar o jornalismo na perspectiva de gênero, como um proponente de tensões, criador de conflitos e estranhamentos sociais, visto que grande parte do jornalismo ainda é regido pela lógica hegemônica do patriarcado.

No entanto, não se pode deixar de mencionar que as temáticas, quando trabalhadas dentro de um editorial de gênero, podem atuar como um recorte dentro do próprio veículo de comunicação, destarte, poderíamos sugerir que o jornal The New York Times está segregando os temas de forma a segmentar o público e de limitar o alcance das notícias publicadas naquele editorial, quando se propõe a trazer temáticas na perspectiva de gênero dentro daquele espaço e não de uma forma ampla e transversalizada em todo o jornal.

É relevante pensar que a pesquisa desenvolvida pelas autoras propõe uma reflexão acerca do fazer jornalístico e das implicações inerentes a esse processo construtivo. A observância e o olhar atento à questão hegemônica e à propositura de fazer do jornalismo um meio de resistência contra-hegemônico pode fomentar os discursos e diálogos em prol de uma representação e representatividade mais justa e plural das mulheres no meio público o que pode resultar no avanço da igualdade entre os gêneros.

\section{Referências}

BARDIN, Laurence. Análise de conteúdo São Paulo. SP: Edições, v. 70, 2011.

BENNET, Jessica. What 18 Looks Like Around the World - Through Girls' Eyes. The New York Times, [S. 1.], p. sn, 11 out. 2018a. Disponível em: https://www.nytimes.com/2018/10/11/world/this-is-18-through-girls-eyes.html. Acesso em: 28 out. 2020.

BENNET, Jessica. 5 Stories of Sex and Consent on Campus. The New York Times, [S. 1.], p. sn, 11 maio 2018b. Disponível em:

https://www.nytimes.com/interactive/2018/05/10/style/sexual-consent-college-campus.html. Acesso em: 28 out. 2020. 
BOURDIEU, P. O poder simbólico. Rio de Janeiro: Bertrand Brasil S.A, 1992.

CUBA, E. Lingüística feminista y apuesta glotopolítica. Anuario de Glotopolítica, v. 2, p. 21-40, 2018.

DEL VALLE, Jose. A política de desconforto. Anuário de Glotopolítica, [S. 1.], p. sn, 21 ago. 2018. Disponível em: https://glotopolitica.com/2018/08/21/la-politica-de-laincomodidad/. Acesso em: 9 nov. 2020.

DE MORAES, Dênis. Comunicação, hegemonia e contra-hegemonia: a contribuição teórica de Gramsci. Revista Debates, v. 4, n. 1, p. 54, 2010.

FEDERAL, Senado. Convenção sobre a eliminação de todas as formas de discriminação contra a mulher. 1979.

GARCIA, Carla Cristina. Breve história do feminismo. Claridade, 2018.

GRAMSCI, Antonio; COUTINHO, Carlos Nelson. Cadernos do cárcere. Rio de Janeiro: Civilização Brasileira, 2000.

MAFFÍA, Diana. Sujetos, política y ciudadanía. In: CHAHER, Sandra; SANTORO, Sonia. Las palabras tienem sexo - introducción a un periodismo con perspectiva de género. Buenos Aires: Artemisa Comunicación Ediciones, 2007.

MEULI, Noelia. Hacia un periodismo con perspectiva de género. Análisis sobre las notícias de violencia de género y femicidio. Question, v. 1, n. 55, p. 472-489, 2017.

MIGUEL, Luis Felipe; BIROLI, Flávia. Feminismo e política: uma introdução. Boitempo Editorial, 2015.

SALAM, Maya. What Is the Equal Rights Amendment, and Why Are We Talking About it now? The New York Times, [S. 1.], p. sn, 22 fev. 2019a. Disponível em:

https://www.nytimes.com/2019/02/22/us/equal-rights-amendment-what-is-it.html. Acesso em: 13 out. 2020

SALAM, Maya. Rebel Women Are Coming to a Public Monument Near You. The New York Times, [S.I.], p. sn, 9 ago. 2018a. Disponível em: https://www.nytimes.com/2018/08/09/us/statues-womenamerica.html?login=smartlock\&auth=login-smartlock\&login=smartlock\&auth=loginsmartlock. Acesso em: 28 out. 2020.

SALAM, Maya. A Record 117 Women Won Office, Reshaping America's Leadership. The New York Times, [S. 1.], p. sn, 7 nov. 2018b. Disponível em: https://www.nytimes.com/2018/11/07/us/elections/women-elected-midterm-elections.html. Acesso em: 28 out. 2020.

SALAM, Maya. Trolls Tried to Sink 'Captain Marvel.' She Triumphed. The New York Times, [S. 1.], p. sn, 15 mar. 2019b. Disponível em: https:/www.nytimes.com/2019/03/15/arts/captain-marvel-trolls.html. Acesso em: 28 out. 2020 . 


\section{RODAL, Asunción Bernardez. Mujeres en Medio (s). Propuesta para analizar la comunicación masiva con Madrid. Fundamentos, 2015.}

RUOHO, Iiris; TORKKOLA, Sinikka. Journalism and Gender. 2018. Disponível em: https://content.sciendo.com/configurable/contentpage/journals $\$ 002$ fnor $\$ 002 \mathrm{f39} \$ 002 \mathrm{f} 1 \$ 002 \mathrm{fa}$ rticle-p67.xml. Acesso em: 2 fev de 2021.

TRAQUINA, Nelson. Teorias do jornalismo. Insular, 2005.

WOITOWICZ, Karina Janz; ROCHA, Paula Melani. Repensar os parâmetros hegemônicos no jornalismo: a perspectiva de gênero na produção jornalística e na formação profissional. In: AGUIAR, Leonel; SILVA, Marcos Paulo da; MARTINEZ, Monica. (Org.).

Desigualdades, relações de gênero e estudos de jornalismo. São Paulo: Life, 2018, v. 1, p. 53-68.

\footnotetext{
i Albertina Vieira de Melo Gomes Oliveira é mestra em Comunicação e Sociedade pelo Programa de Pós-Graduação em Comunicação e Sociedade da Universidade Federal do Tocantins (PPGCOM/UFT), participa do grupo de pesquisa Comunicação, Direitos e Igualdade (CODIG) -UFT, coordenado pela professora Dra Cynthia Mara Miranda. É graduada em Comunicação Social pela UFT (2005), possui MBA em Comunicação Empresarial e Marketing. Participou do Global Media Monitoring Project (GMMP) 2020. Participa da Rede Brasileira de Jornalistas com Visão de Gênero e da Red Internacional de Periodistas com Vision de Género (RIPVG). No período de 2007 a 2009 foi professora do curso de Publicidade e Propaganda da Faculdades Objetivo e Fapal em Palmas, Tocantins. Atualmente é pesquisadora do Laboratório de Estudos Geopolíticos da Amazônia Legal (LEGAL).
}

ii Possui graduação em Comunicação Social pela Universidade Federal do Tocantins, mestrado e doutorado em Ciências Sociais pela Universidade de Brasília. Pós-doutorado em Comunicação pelo Programa de Pós-Graduação em Comunicação da Universidade Federal de Minas Gerais (PPGCOM/UFMG) com bolsa da Capes por meio do Programa Nacional de Cooperação Acadêmica na Amazônia (Procad-Am). Atualmente é professora Associada I da Universidade Federal do Tocantins atuando no curso de Jornalismo e no Programa de Pós-Graduação em Comunicação e Sociedade. Foi editora e presidenta do Conselho Editorial da Editora da Universidade Federal do Tocantins de maio de 2018 até agosto de 2019. Líder do grupo de pesquisa Comunicação, Direitos e Igualdade (CODIG), pesquisadora do Coletivo 50 graus - Pesquisa e Prática fotográfica e coordenadora da Rede Brasileira de Jornalistas com Visão de Gênero. Membro fundadora da Réseau de Recherche sur les Genres et les Territoires (REGENT) Canadá, membro da Rede de Pesquisas em Feminismos e Política e membro da Red Internacional de Periodistas con Visión de Género (RIPVG) na qual integra a Comissão de Pesquisa e membro da Global Alliance on Media and Gender (GAMAG) na Regional América Latina. GAMAG é rede mundial de pessoas e organizações lançada pela Unesco para atuar pelo avanço da igualdade de gênero na mídia e nas TICs. É integrante da coordenação colegiada da Rede Brasileira de Jornalistas e Comunicadoras com visão de Gênero e Raça e coordenou um grupo regional no Projeto de Monitoramento Global dos Media (GMMP) 2020. Tem experiência nas seguintes áreas de estudo: comunicação e jornalismo na perspectiva de gênero, narrativas da violência contra mulher, mídia e política, movimentos sociais, desenvolvimento regional na perspectiva de gênero, políticas públicas de comunicação, igualdade e de juventude. 